\title{
25 Research Square \\ Isolation, molecular and phylogenetic analysis of porcine encephalomyocarditis virus strain HLJ in China
}

\section{Xueting Yin}

Northeast Agricultural University

Peng Liu

Northeast Agricultural University

Haixin Liu

Northeast Agricultural University

Yue Zhang

Northeast Agricultural University

\section{Ghulam Abbas}

Northeast Agricultural University

Ishfaq Muhammad

Northeast Agricultural University

\section{Yudong Ren}

Northeast Agricultural University

Xiaodan Huang

Northeast Agricultural University

Ruili Zhang

Northeast Agricultural University

Guangxing Li ( $\square$ ligx@neau.edu.cn )

Northeast Agricultural University, College of Veterinary Medicine; https://orcid.org/0000-0002-56447675

\section{Research}

Keywords: EMCV, Isolation, Molecular characterization, Phylogenetic analysis

Posted Date: April 27th, 2020

DOI: https://doi.org/10.21203/rs.3.rs-24699/v1

License: (c) (1) This work is licensed under a Creative Commons Attribution 4.0 International License. Read Full License 


\section{Abstract \\ Background}

Encephalomyocarditis virus (EMCV) is a positive single-stranded small RNA virus without envelope, which can infect a variety of mammals. Swine are the most susceptible animals, which can cause acute myocarditis and respiratory failure in piglets and reproductive failure in pregnant sows. Diseases caused by EMCV have a wide range of effects on the global swine industry.

\section{Methods}

The tissue grinding fluid of aborted fetus was inoculated on baby hamster kidney 21 (BHK-21) cells to obtain $\mathrm{HLJ}$ isolate by cell passage. The virus was identified by reverse transcriptase polymerase chain reaction (RT-PCR), electron microscopic observation and indirect immunofluorescence assay (IFA). HLJ strain was inoculated into mice for animal regression experiment. The whole genome of HLJ strain was amplified and sequenced. The molecular and phylogenetic analysis of its sequence was generated.

\section{Results}

HLJ strain caused the specific cytopathic effect (CPE) on BHK-21 cells and severe pathological changes in mice. Complete genome sequencing and multiple sequence alignment showed that the homology between HLJ strain and other isolates worldwide was 71.5-99.7\%. Phylogenetic analysis showed that EMCV isolates fell into five clusters: lineage I, II, III, IV, and V based on the nucleotide sequences of the entire open reading frame (ORF) and VP1 gene. HLJ isolate was grouped into lineage I.

\section{Conclusions}

In this study, a strain of EMCV was isolated from an aborted fetus in Northeast China. The isolation of HLJ strain enriches the epidemiological database of EMCV.

\section{Background}

Encephalomyocarditis virus (EMCV) is an animal pathogen, which is characterized by encephalitis, myocarditis or sudden death [1, 2]. EMCV was first diagnosed in Florida in 1945 from a gibbon and then isolated and investigated in many countries $[3,4]$. Since the epidemic of EMCV, researchers reported that it can cause a variety of animal diseases in a variety of hosts including livestock, rodents and wild animals [5-9]. Besides piglets are susceptible to EMCV, rodent mice and rats are natural hosts of EMCV. The virus can cause acute myocarditis or even acute death in piglets with a mortality rate of $100 \%$ [10]. In mice, EMCV caused mainly myocarditis, neurovirulence, and diabetes [11-13]. 
EMCV belongs to the genus Cardiovirus of the family Picornaviruses. The virus particle is icosahedral symmetrical, non-encapsulated and about $27 \mathrm{~nm}$ in diameter, with a bare viral capsid on the periphery[14]. EMCV is a single-stranded RNA virus [15]. The full length of the genome encodes a large ORF of about $7.8 \mathrm{~kb}$ flanked by the 5' UTR and 3' UTR of the untranslated region [16]. The genomic structure is that $5^{\prime}$ UTR connects to the guiding protein $L$, which inhibits the accumulation of stress particles produced by EMCV infection. Downstream is linked to a poly (C) tract and an internal ribosomal entry site (IRES) type II, EMCV structure without cap relies on IRES as the starting point of protein translation [17]. The $3^{\prime}$ UTR is about 120 bp long, and the polyadenylation at the end forms a poly $(A)$ structure, which functions to stabilize mRNA and initiate RNA replication, and is related to the infectivity of the virus [18]. The proteins encoded by ORF contain non-structural proteins and structural proteins, which are divided into three precursor molecules P1, P2 and P3. The genome encodes a total of 11 different proteins. The $\mathrm{P} 1$ region protein constitutes the virus capsid, which is the main antigenic site of the virus, and is closely related to the adsorption and pathogenicity of the virus. P2 and P3 region are mainly viral genome replication related proteins and polyprotein cleavage related proteins $[19,20]$.

In recent years, EMCV infection in swine industry is increasing at an alarming rate. In addition, it also infects human beings. This study describes the isolation, genomic sequencing and bioinformatics analysis of an EMC virus, HLJ isolate, from an aborted fetus. The strain has high pathogenicity to mice.

The whole genome and deduced amino acid sequences of HLJ strain were compared with the nucleotide and amino acid sequences of typical EMCV strains from different countries. This study revealed the molecular evolution characteristics of HLJ strain and provided a reference for the prevention and control of EMCV in the future.

\section{Methods}

\section{Virus isolation and titration}

A piece of myocardium of aborted fetus was homogenized in phosphate-buffered saline (PBS) using a glass homogenizer. The suspension was repeatedly frozen and thawed 3 times, followed by clarification through a $0.22-\mu \mathrm{m}$ filter, and $1 \%$ antibiotic was added. Confluent BHK-21 cells in 6-well plates were inoculated with $300 \mu \mathrm{L}$ of sample and $100 \mu \mathrm{L}$ of medium. After $45 \mathrm{~min}$, another $1.0 \mathrm{~mL}$ of complete growth medium was added to each well in the 6-well plate. Inoculated cells were incubated at $37^{\circ} \mathrm{C}$ with $5 \% \mathrm{CO}_{2}$. When a $70 \% \mathrm{CPE}$ developed, the plates were subjected three times to freezing and thawing. The mixtures were centrifuged at $3,000 \times \mathrm{g}$ for $10 \mathrm{~min}$ at $4{ }^{\circ} \mathrm{C}$. The supernatants were harvested for further propagation. Inoculated cells at each passage were tested using an RT-PCR assay. Virus titration was performed in 96-well plates with 10 -fold serial dilutions performed in triplicate per dilution. Virus titers were determined according to the Reed and Muench method and expressed as the median tissue culture infective dose $\left(\mathrm{TCID}_{50}\right) / 100 \mu \mathrm{L}$. 


\section{Electron Microscopy (em) And Indirect Immunofluorescence Assay (ifa)}

Samples were prepared for negative staining examination by electron microscopy (EM). BHK-21 cells were infected with the third generation virus of HLJ isolate, frozen and thawed $48 \mathrm{~h}$ later, and centrifuged at $3,000 \times \mathrm{g}$ for $10 \mathrm{~min}$. The supernatant was harvested and the virus was granulated from the supernatant by ultracentrifugation at $159,000 \times \mathrm{g}$ for $1.5 \mathrm{~h}$ at $4{ }^{\circ} \mathrm{C}$. The resulting pellet was resuspended in $500 \mu \mathrm{l}$ of $0.01 \mathrm{M}$ PBS (pH 7.2 to 7.4), which was atomized onto coated EM grids. The grids were stained with $1 \%$ phosphotungstic acid $(\mathrm{pH} \mathrm{7.0)}$ ) and observed with a transmission electron microscope.

After $12 \mathrm{~h}$ post-infection, the infected BHK-21 cells were fixed with $4 \%$ formaldehyde for $30 \mathrm{~min}$ at room temperature. The cells were treated with glycine for $6 \mathrm{~min}$ and permeated by $0.1 \%$ Triton for $10 \mathrm{~min}$. The cells were incubated with EMCV-specific rabbit polyclonal antibody (1:200 dilution) for $1 \mathrm{~h}$ and incubated with fluorescein isothiocyanate (FITC) labeled goat anti-rabbit IgG (1:100 dilution; Sigma-Aldrich) for $1 \mathrm{~h}$ at $37^{\circ} \mathrm{C}$, then re-stained the nucleus with DAPI (Beyotime, China). It was observed under an inverted fluorescence microscope. EMCV-specific rabbit polyclonal antibody was prepared in our laboratory.

\section{Mice And Infection Experiment}

Female Kunming mice, aged 4 to 6 weeks, were intraperitoneally infected with $200 \mu \mathrm{L} H \mathrm{LJ}$ strain at the concentration of $2 \times 10^{4} \mathrm{TCID}_{50}$ (I.P.) or Dulbecco modified Eagle medium (DMEM, Gibco, USA). The 25 mice were randomly divided into two groups. The one group of twenty mice was each inoculated with the virus and the other group of five mice was inoculated with DMEM as negative control. The brain and heart tissues of mice that died of EMCV infection were harvested on the day of death. Negative control mice were euthanized at the end of the experiment.

\section{Immunofluorescence Of Fresh Frozen Tissue And Histological Examination}

The dying mice were dissected and their internal organs were examined. The fresh brain and myocardial tissue materials were immediately embedded in optimal cutting temperature compound and then made into frozen sections with a thickness of $6 \mu \mathrm{m}$. After acetone fixation, indirect immunofluorescence experiment was carried out. The sections were treated with EMCV-specific polyclonal antibody and FITCconjugated goat anti-rabbit IgG, then re-stained the nucleus with DAPI. After sealing, the sections were observed under positive fluorescence microscope. In addition, brain and myocardial tissue samples were fixed with $10 \%$ formalin, embedded in paraffin, sliced on Leica RM $2125 \mathrm{RT}$ slicing machine, dewaxed and hematoxylin-eosin (HE) staining according to the standard procedure. 


\section{Nucleotide Sequence Analysis}

EMCV-specific primers were designed based on the ORF of the BJC3 strain (DQ464062). The whole genome of HLJ stain was amplified and sequenced using a set of specific primers (Additional file 1: Table S1). DNA fragments corresponding to the complete nucleotide sequences of HLJ strain were amplified in sections, ligated with the pMD18-T vector (Takara, Japan) to construct a recombinant plasmid and the amplicons were sequenced commercially (JinWeizhi, Suzhou). Sequence assembly was competed by means of the SeqMan program included with the DNASTAR software. Multiple sequence alignment based on the ORFs, and each coding gene sequence of HLJ and other $23 \mathrm{EMCV}$ reference strains (Table 1) was conducted using DNAStar software. Subsequent phylogenetic analysis was performed on the ORFs and VP1 genes using the distance-based neighbor-joining method in the MEGA5 software package. Bootstrap analysis was carried out on 1,000 replicate data sets. The amino acid sequence of VP1 protein of HLJ isolate was compared with those of different EMCV strains in China.

Table 1

Encephalomyocarditis virus isolates used in this study. 


\begin{tabular}{|c|c|c|c|c|}
\hline $\begin{array}{l}\text { Isolate } \\
\text { name }\end{array}$ & $\begin{array}{l}\text { Accession } \\
\text { number }\end{array}$ & $\begin{array}{l}\text { Geographic } \\
\text { origin }\end{array}$ & Species & $\begin{array}{l}\text { Collection year /Submission } \\
\text { year }\end{array}$ \\
\hline Mengo-M & L22089 & Uganda & Monkey & 1948/1993 \\
\hline EMCV-R & M81861 & USA & Chimpanzee & $1945 / 2000$ \\
\hline EMCV-B & M22457 & USA & Swine & 1980/1989 \\
\hline EMCV-D & M22458 & USA & Swine & 1980/1989 \\
\hline D variant & M37588 & USA & Swine & 1980/1988 \\
\hline EMCV-30 & AY296731 & USA & Swine & $1987 / 2003$ \\
\hline pEC9 & DQ288856 & USA & Mice & $1995 / 2005$ \\
\hline Rz-pMwt & DQ294633 & USA & Mice & $2005 / 2005$ \\
\hline PV2 & X87335 & Germany & Swine & 1985/1995 \\
\hline RD1338 & JX257003 & Germany & $\begin{array}{l}\text { Wood } \\
\text { mouse }\end{array}$ & $2005 / 2012$ \\
\hline $\begin{array}{l}\text { Sing-M105- } \\
02\end{array}$ & KC310738 & Singapore & Orangutan & $2002 / 2012$ \\
\hline $\begin{array}{l}\text { Sing-M100- } \\
02\end{array}$ & KC310737 & Singapore & Orangutan & $2002 / 2012$ \\
\hline HN13 & KF771002 & China & Wild boar & $2013 / 2013$ \\
\hline BJC3 & DQ464062 & China & Swine & $2005 / 2006$ \\
\hline HB1 & DQ464063 & China & Swine & $2005 / 2006$ \\
\hline GX0602 & FJ604853 & China & Mice & $2006 / 2009$ \\
\hline JZ1202 & KF836387 & China & Boar & $2012 / 2013$ \\
\hline$J Z 1203$ & KF836388 & China & Mice & $2012 / 2013$ \\
\hline YY13 & KF836390 & China & Swine & $2013 / 2013$ \\
\hline YM13 & KF836389 & China & Swine & $2013 / 2013$ \\
\hline BD2 & KF709977 & China & Swine & $2013 / 2013$ \\
\hline FJ13 & KF293299 & China & Tigers & $2013 / 2013$ \\
\hline GS01 & KJ524643 & China & Swine & $2014 / 2014$ \\
\hline
\end{tabular}

\section{Results}

\section{Virus isolation and characterization}


An EMCV strain named HLJ was isolated from the heart tissue of aborted fetus from breeding farm in Heilongjiang province of China (collected in March 2016) which had shown positive RT-PCR results (data not displayed). After three passages on BHK-21 cells, the virus titer of HLJ strain grew to $10^{8.3} \mathrm{TCID}_{50}$ on BHK-21 cells (Fig. 1A). And HLJ strain caused specific cytopathic effects (CPE) within 24 h (Fig. 1B. b). After BHK-21 cells were infected with HLJ strain for $48 \mathrm{~h}$, the ultra-thin sections were prepared. Under transmission electron microscope, it was found that the virus particles were located in the cytoplasm. The virions were arranged in a lattice (Fig. 2A). The growth of the virus was confirmed by IFA with EMCVspecific polyclonal antibody. The BHK-21 cells inoculated with HLJ strain showed specific green fluorescence (Fig. 2B).

\section{Characteristics Of Hlj Strain Virus In Vivo}

The results showed that some mice in the attack group began to show clinical symptoms on the 3rd day, such as depression, wrinkled fur, loss of appetite, tears, hunchback posture, abnormal gait, hindlimb paralysis and quadriplegia, and death (Fig. 3A. b). The mice in the negative control group did not have any clinical symptoms and all survived (Fig. 3A. a). After autopsy, the heart of the infected mice was soft, and there were white punctate necrotic foci on the surface (Fig. 3B. d). In addition, the brain was congested and swollen (Fig. 3B. b), and there were no obvious pathological changes in other tissues. After HE staining, the brain of mice in the infected group was mainly characterized by extensive atrophy and necrosis of nerve cells in the cortical area, accompanied by extensive glial cell infiltration, obvious satellite phenomenon, nerve phagocytosis and microglial nodules, and typical vascular sheath phenomenon around blood vessels. Myocardial tissue showed diffuse inflammatory cell infiltration, local cell degeneration and necrosis, hemorrhage and disintegration of myocardial fibers (Fig. 3C). Indirect immunofluorescence results showed that green fluorescence signals could be detected in brain and heart tissues of the infected group (Fig. 3D). In conclusion, the virus was successfully isolated from the myocardium of dead aborted fetuses, and the virus was lethal to mice.

\section{Whole Genome Sequencing And Genomic Characterization Of Hlj Strain}

Five fragments covering the complete genome of HLJ strain were amplified by RT-PCR method and sequenced. After splicing the above sequencing results, the whole genome nucleic acid sequence of HLJ strain was obtained, and the accession number of GenBank is MH191297. The full-genome sequence of HLJ strain is 7746 bp long, with a 5' UTR of 717 bp, a 3' UTR of 138 bp, and encodes 2,292 amino acids. The ORF of $6879 \mathrm{bp}$ encodes 11 proteins which are similar to those of the previous reported EMCV strains. HLJ strain showed high sequence homology (99.2-99.7\%) with BD2, BJC3, EMCV-R, FJ13, GS01, HB1, GX0602, HN13, JZ1202, JZ1203, pEC9, YM13 and YY13, and lower sequence homology (71.584.6\%) with EMCV-B, EMCV-D, D variant, EMCV-30, Mengo-M, Rz-pMwt, RD 1338, PV2, Sing-M100-02, and Sing-M105-02 (Additional file 2: Table S2). The non-structural protein was more conservative than the 
structural protein coding region, and the VP1 protein had the greatest variation in the structural protein. On the other hand, 2A protein had the greatest variation in non-structural protein. The stable genomic structure of 3D protein is the most conserved protein of all proteins.

\section{Phylogenetic analysis of HLJ strain and structural analysis of the VP1 protein}

The results of phylogenetic analysis showed that, HLJ strain and other reference strains were divided into five clusters (lineage I, II, III, IV, and V) based on the nucleotide sequences of ORF and VP1 gene. HLJ isolate was grouped into lineage I. Lineage I comprises all the Chinese isolates, American isolates pEC9, EMCV-R, and EMCV-30. HLJ strain was more closely related to GS01 strain in phylogenetic analysis based on the ORF nucleotide sequences. HLJ strain was most closely related to HN13 strain in phylogenetic analysis based on the nucleotide sequences of VP1 gene (Fig. 4). Structural analysis of the VP1 protein of HLJ strain showed that it had two new mutations at 20 and 54 amino acid positions compared with the other strains (Table 2).

\section{Table 2}

The amino acid mutation site of VP1 protein of HLJ strain 


\begin{tabular}{|c|c|c|c|c|c|c|c|c|}
\hline $\begin{array}{l}\text { Amino acid } \\
\text { Strains }\end{array}$ & 3 & 7 & 13 & 20 & 54 & 63 & 120 & 212 \\
\hline EMCV HLJ & E & $\mathrm{K}$ & $\mathrm{T}$ & $\mathrm{L}$ & $\mathrm{K}$ & E & $\mathrm{F}$ & G \\
\hline GX0602 & $\mathrm{E}$ & $\mathrm{K}$ & A & V & $\mathrm{E}$ & Q & $\mathrm{F}$ & E \\
\hline JZ1203 & $\mathrm{E}$ & $\mathrm{R}$ & $\mathrm{T}$ & V & $E$ & $\mathrm{R}$ & $\mathrm{F}$ & G \\
\hline PEC9 & $\mathrm{E}$ & $\mathrm{K}$ & $\mathrm{T}$ & V & $E$ & G & $\mathrm{F}$ & G \\
\hline BD2 & $\mathrm{E}$ & $\mathrm{K}$ & v & V & $E$ & G & $\mathrm{F}$ & G \\
\hline BJC3 & $\mathrm{E}$ & $\mathrm{K}$ & A & V & $E$ & G & $Y$ & G \\
\hline GS01 & $\mathrm{E}$ & $\mathrm{K}$ & A & V & $E$ & $\mathrm{Q}$ & $\mathrm{F}$ & G \\
\hline HB1 & $\mathrm{E}$ & $\mathrm{K}$ & A & V & $E$ & G & $\mathrm{F}$ & G \\
\hline HN13 & $\mathrm{E}$ & $\mathrm{K}$ & $\mathrm{T}$ & V & $E$ & $\mathrm{Q}$ & $\mathrm{F}$ & G \\
\hline JZ1202 & $\mathrm{E}$ & $\mathrm{K}$ & $\mathrm{T}$ & V & $E$ & G & $\mathrm{F}$ & G \\
\hline YM13 & $\mathrm{E}$ & $\mathrm{K}$ & A & V & $E$ & $\mathrm{E}$ & $\mathrm{F}$ & G \\
\hline YY13 & D & K & $\mathrm{T}$ & V & $E$ & G & $\mathrm{F}$ & G \\
\hline
\end{tabular}

\section{Discussion}

EMCV displays a wide spectrum of host and disease, as it is able to infect nonhuman primates, swine, boars, rodents, and elephants, and human infections have also been reported [21]. Pigs are susceptible animals that can easily lead to myocarditis, reproductive failure and high mortality in pregnant sows, fetuses and weaned piglets [16]. EMCV infection has been detected in many swine farms by etiological and serological methods $[22,23]$. Therefore, the isolation and identification of endemic strains and genome-wide sequence analysis can enrich the accumulation of EMCV molecular epidemiology and bioinformatics research data.

In this study, HLJ strain was isolated from an aborted fetus, and it was continuously propagated and identified by cell culture. We clearly proved that HLJ strain has phenotypic and genetic stability in cell culture through a series of studies. Also, the results of animal regression experiment showed that HLJ strain had strong pathogenicity to mice, which was consistent with the results of previous studies [8, 24]. The amplification of the whole genome sequence is the basis for further study of the virus. Fang and others used the strategy of segmented cloning to construct an infectious clone of NJ08 strain [25]. Next, we plan to use the segmented cloning strategy to amplify the full length of HLJ strain and construct an infectious clone for further study of the pathogenic mechanism of EMCV. 
The results of genome-wide homology analysis showed that HLJ strain was highly homologous to the domestic swine source and mouse source. It is suggested that it can infect a variety of hosts, and there may be cross-infection, in which rodents have a wide range of activities, high mobility and other characteristics that may be major factors in the spread of EMCV [26]. Nucleotide and deduced amino acid homology analysis of each gene showed that 2A protein was the least conserved protein of nonstructural proteins. Some studies have shown that the method of continuous passage of attenuated virus has found that 2A protein can still infect cells after the deletion of 127 amino acids and 12 amino acid mutations, but has no pathogenicity to mice, indicating that 2A protein is related to the pathogenicity of mice $[24,27]$. This may be the method of developing attenuated live vector vaccine.

Comprehensive phylogenetic analysis showed that, HLJ strain was located in lineage I, which was closely related to wild boar HN13 or swine GS01 strain. It may be a genetic variation from wild boar to domestic boar. The two Singaporean orangutan EMCV isolates were grouped in lineage IV. All the western strains were in the lineage II, III, and V, indicating that geographical factors and hosts affect the genetic evolution of EMCV. Therefore, the geographical location of genetic variation of EMCV occupies the main factor, followed by transmission host, and there is cross infection. In addition, the mutation of EMCV VP1 protein is also the research direction that people have been studying. It has been reported that amino acid mutations of VP1 protein can cause pathogenic changes in mice [28]. So, our results showed two new mutation points of VP1 protein of HLJ strain that may cause pathogenic changes.

\section{Conclusion}

EMCV causes acute myocarditis and respiratory failure in piglets and reproductive disorders in pregnant sows. At present, there are no effective drugs and vaccines for the prevention and control of the disease. In this study, HLJ strain was isolated from an aborted fetus. The virus has high pathogenicity and lethality to mice. Phylogenetic analysis showed that HLJ strain was located in lineage I, with all the Chinese isolates and a few American isolates. Geographical location is the main factor affecting the genetic variation of EMCV. Isolation and identification of EMCV HLJ strain and molecular biology analysis can lay a theoretical and material basis for the development of new and efficient approaches for the disease prevention.

\section{Abbreviations}

BHK-21 cells: Baby hamster kidney 21 cells; CPE: Cytopathic effect; DMEM: Dulbecco modified Eagle medium; EM: Electron microscopy; EMCV: Encephalomyocarditis virus; FITC: Fluorescein isothiocyanate; HE: hematoxylin-eosin; IFA: Indirect immunofluorescence assay; IRES: Internal ribosomal entry site; ORF: Open reading frame; PBS: Phosphate-buffered saline; RT-PCR: Reverse transcriptase polymerase chain reaction; TCID50: Median tissue culture infective dose

\section{Declarations}


Acknowledgements

Not applicable.

\section{Authors' contributions}

Peng Liu, Xueting Yin, Haixin Liu and Yue Zhang carried out the study. Xueting Yin drafted the manuscript. Ishfaq Muhammad and Ghulam Abbas helped to correct the grammatical errors in the manuscript. Guangxing Li, Yudong Ren, Xiaodan Huang, and Ruili Zhang conceived the study and participated in its design and coordination. All authors read and approved the final manuscript.

\section{Funding}

This work was supported by the programme for National Natural Science Foundation of China (31270187; 31372438); National Science \& Technology Pillar Program during the Twelfth Five-year Plan Period (2013BAD12B04).

\section{Availability of data and materials}

All relevant data are provided in this manuscript. If required, the data are available from the corresponding author.

\section{Ethics approval and consent to participate}

Animal experimental procedures were approved by the Institutional Animal Ethical Committee of Northeast Agricultural University (Number SRM-08). All animal studies were complied with the animal experiment guidelines of the Animal Experimentation Ethics Committee of Northeast Agricultural University.

\section{Consent for publication}

Not applicable.

\section{Competing interests}

The authors declare that they have no competing interests. 


\section{References}

1. Baggen J, Thibaut HJ, Hurdiss DL, Wahedi M, Marceau CD, van Vliet ALW, Carette JE, van Kuppeveld FJM. Identification of the cell-surface protease ADAM9 as an entry factor for encephalomyocarditis virus. mBio. 2019;10:e01780-01719.

2. Francisco E, Suthar M, Gale M, Rosenfeld AB, Racaniello VR. Cell-type specificity and functional redundancy of RIG--like receptors in innate immune sensing of Coxsackievirus B3 and encephalomyocarditis virus. Virology. 2019;528:7-18.

3. Helwig FC, Schmidt CH. A filter-passing agent producing interstitial myocarditis in Anthropoid Apes and small animals. Science. 1945;102:31-3.

4. Murnane TG, Craighead JE, Mondragon H, Shelokov A. Fatal disease of swine due to encephalomyocarditis virus. Science. 1960;131:498-9.

5. Larue R, Myers S, Brewer L, Shaw DP, Brown C, Seal BS, Njenga MK. A wild-type porcine encephalomyocarditis virus containing a short poly $(\mathrm{C})$ tract is pathogenic to mice, pigs, and cynomolgus macaques. J Virol. 2003;77:9136-46.

6. Maurice H, Nielen M, Brocchi E, Nowotny N, Kassimi LB, Billinis C, Loukaides P, O'Hara R, Koenen S. F. The occurrence of encephalomyocarditis virus (EMCV) in European pigs from 1990 to 2001. Epidemiol Infect. 2005;133:547-57.

7. Billinis C. Encephalomyocarditis virus infection in wildlife species in Greece. J Wildl Dis. 2009;45:522-6.

8. Canelli E, Luppi A, Lavazza A, Lelli D, Cordioli P. Encephalomyocarditis virus infection in an Italian zoo. Virol J. 2010;7:64.

9. Zhang H, Wang X, Li X, Ma Z, Feng R. Construction, expression, and characterization of a singlechain variable fragment (ScFv) antibody targeting to the encephalomyocarditis virus. J Med Virol. 2018;90:1184-91.

10. Li X, Ma R, Li Q, Li S, Zhang H, Xie J, Bai J, Idris A, Feng R. Transmembrane protein 39A promotes the replication of encephalomyocarditis virus autophagy pathway. Front Microbiol. 2019;10:2680.

11. Noguchi K, Tomita H, Kanayama T, Niwa A, Hatano Y, Hoshi M, Sugie S, Okada H, Niwa M, Hara A. Time-course analysis of cardiac and serum galectin-3 in viral myocarditis after an encephalomyocarditis virus inoculation. PLoS One. 2019;14:e0210971.

12. Cerutis DR, Bruner RH, Thomas DC, Giron DJ. Tropism and histopathology of the D, B, K, and MM variants of encephalomyocarditis virus. J Med Virol. 1989;29:63-9.

13. Yoon JW. The role of viruses and environmental factors in the induction of diabetes. Curr Top Microbiol Immunol. 1990;164:95-123.

14. van der Grein SG, Defourny KAY, Rabouw HH, Galiveti CR, Langereis MA, Wauben MHM, Arkesteijn GJA, van Kuppeveld FJM. Nolte-'t Hoen ENM. Picornavirus infection induces temporal release of multiple extracellular vesicle subsets that differ in molecular composition and infectious potential. PLoS Pathog. 2019;15:e1007594. 
15. Bazzone LE, King M, MacKay CR, Kyawe PP, Meraner P, Lindstrom D, Rojas-Quintero J, Owen CA, Wang JP, Brass AL, et al. A disintegrin and metalloproteinase 9 domain (ADAM9) is a major susceptibility factor in the early stages of encephalomyocarditis virus infection. mBio. 2019;10:e02734-18.

16. Liu H, Li Y, Zhang G, Sang S, Wang C, Chang H. Complete genome sequences and phylogenetic analysis of encephalomyocarditis virus strains isolated from pigs and rats origin. Infect Genet Evol. 2017;55:277-80.

17. Ghassemi F, Madadgar O, Roohvand F, Rasekhian M, Etemadzadeh MH, Boroujeni GRN, Langroudi AG, Azadmanesh K. Translational efficiency of BVDV IRES and EMCV IRES for T7 RNA polymerase driven cytoplasmic expression in mammalian cell lines. Mol Biol (Mosk). 2017;51:324-33.

18. Li L, Fan H, Song Z, Liu X, Bai J, Jiang P. Encephalomyocarditis virus $2 \mathrm{C}$ protein antagonizes interferon- $\beta$ signaling pathway through interaction with MDA5. Antiviral Res. 2019;161:70-84.

19. Carmody M, Zimmer JT, Cushman $\mathrm{CH}$, Nguyen T, Lawson TG. The ubiquitin-protein ligase E6AP/UBE3A supports early encephalomyocarditis virus replication. Virus Res. 2018;252:48-57.

20. Luo YK, Liang L, Tang QH, Zhou L, Shi LJ, Cong YY, Lin WC, Cui SJ. Isolation and Characterization of Encephalomyocarditis Virus from Dogs in China. Sci Rep. 2017;7:438.

21. Oberste MS, Gotuzzo E, Blair P, Nix WA, Ksiazek TG, Comer JA, Rollin P, Goldsmith CS, Olson J, Kochel TJ. Human febrile illness caused by encephalomyocarditis virus infection, Peru. Emerg Infect Dis. 2009;15:640-6.

22. Yuan W, Wang J, Sun M, Zheng Y, Li L, Zhang X, Sun J. Rapid detection of encephalomyocarditis virus by one-step reverse transcription loop-mediated isothermal amplification method. Virus Res. 2014;189:75-8.

23. Feng R, Zhang H, Wei J, Li X, Xie J, Li M, Qiao Z, Feng Y, Ma Z. Isolation, molecular and phylogenetic analysis of encephalomyocarditis virus strain GS01 in China. Infect Genet Evol. 2015;30:19-26.

24. Carocci M, Cordonnier N, Huet H, Romey A, Relmy A, Gorna K, Blaise-Boisseau S, Zientara S, Kassimi LB. Encephalomyocarditis virus 2A protein is required for viral pathogenesis and inhibition of apoptosis. J Virol. 2011;85:10741-54.

25. Fang P, Bai J, Liu X, Dong J, Sun T, Jiang P. Construction and characterization of an infectious CDNA clone of encephalomyocarditis virus from pigs in China. Arch Virol. 2015;160:805-9.

26. Maurice H, Thulke HH, Schmid JS, Stegeman A, Nielen M. The impact of compartmentalised housing on direct encephalomyocarditis virus (EMCV) transmission among pigs; insight from a model. Prev Vet Med. 2016;127:105-12.

27. Napthine S, Bell S, Hill CH, Brierley I, Firth AE. Characterization of the stimulators of protein-directed ribosomal frameshifting in Theiler's murine encephalomyelitis virus. Nucleic Acids Res. 2019;47:8207-23.

28. Zhu S, Ge X, Gong X, Guo X, Chen Y, Yang H. Alteration of encephalomyocarditis virus pathogenicity due to a mutation at position 100 of VP1. Sci China Life Sci. 2011;54:535-43. 


\section{Figures}

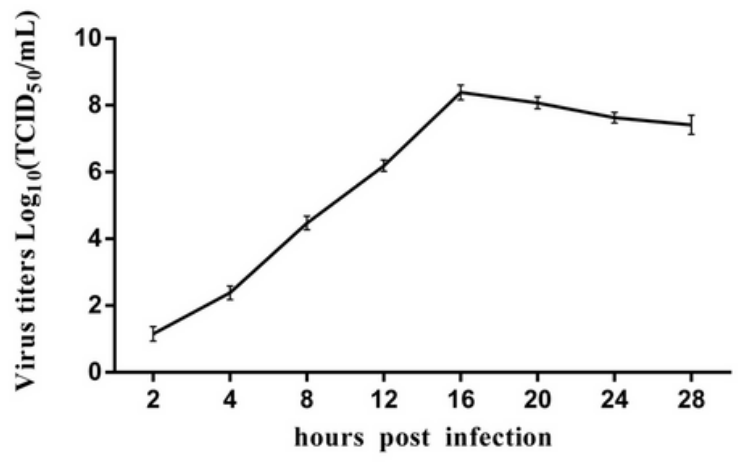

$\mathbf{A}$

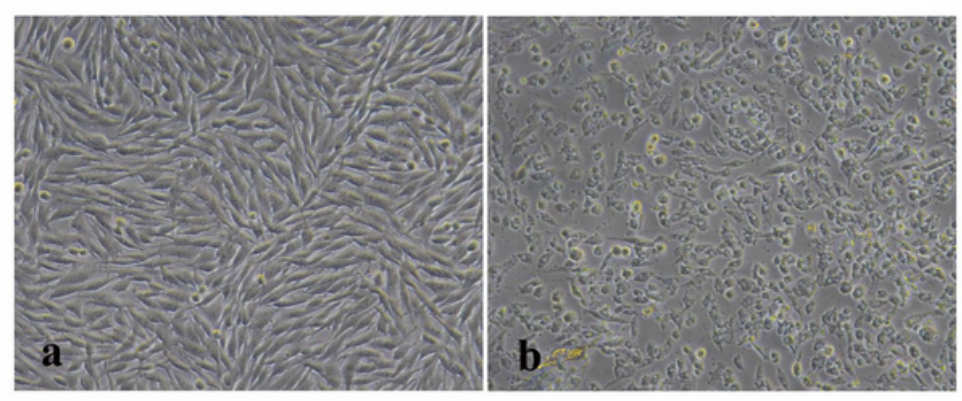

B

\section{Figure 1}

Virus isolation and titration (A) One-step growth curve of HLJ strain on BHK-21 cells. BHK-21 cells in 96well plates were infected with a series of 10-fold dilution of the virus, the culture supernatants were harvested at indicated time points and the viral titers were determined by TCID50. SD bars are shown for triplicate independent trials. (B) BHK-21 cells were cultured to $80 \%$ monolayer and inoculated with HLJ strain. The CPE was observed within 48 h. (a) negative control BHK-21 cells (20x magnification); (b) HLJ strain infected BHK-21 cells (20x magnification).

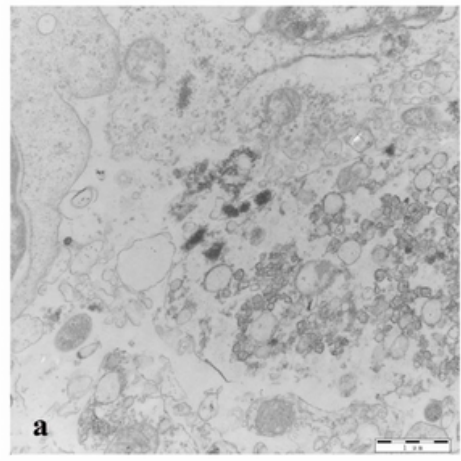

$\mathbf{A}$
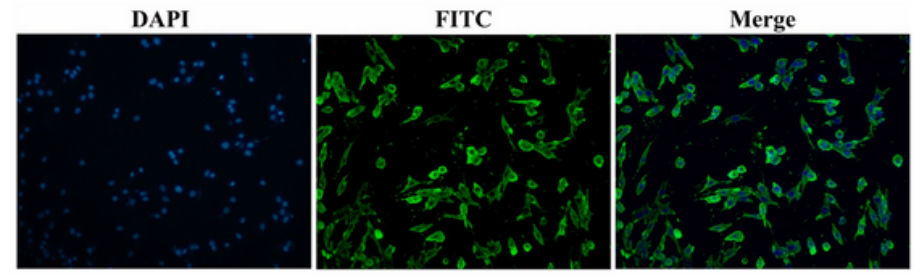

B

\section{Figure 2}

Electron micrographs and immunofluorescence detection (A) Electron micrographs showing the virus particle of HLJ strain. Virus was concentrated from the tissue culture fluid of virus-infected BHK-21 cells. (a) virus particles of HLJ strain (Scale bar represents $1 \mu \mathrm{m}$ ); (b) virus particles of HLJ strain (Scale bar represents $500 \mathrm{~nm}$ ). (B) Immunofluorescence detection of replication for HLJ strain on BHK-21 cells at 12 h post inoculation (20x magnification). The BHK-21 cells were treated with EMCV-specific polyclonal antibody and FITC-conjugated goat anti-rabbit IgG (green), then re-stained the nucleus (blue) with DAPI. 


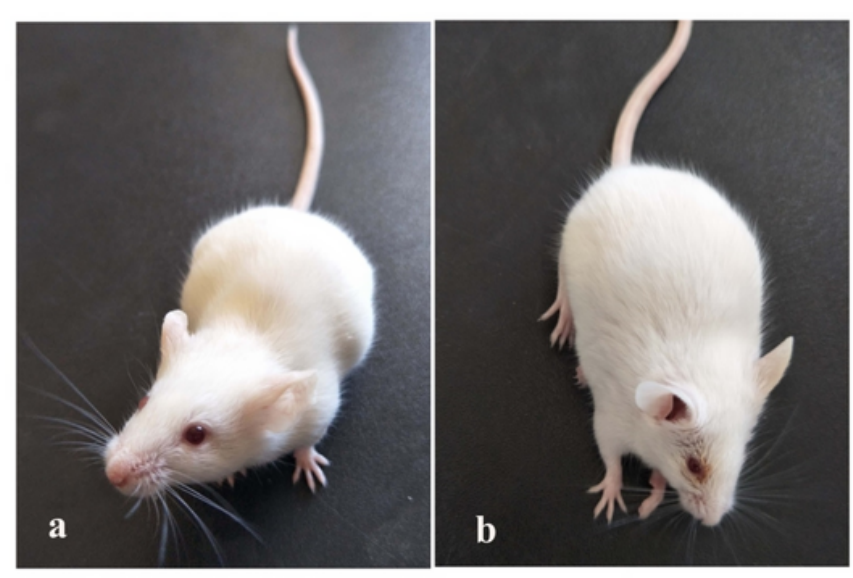

A

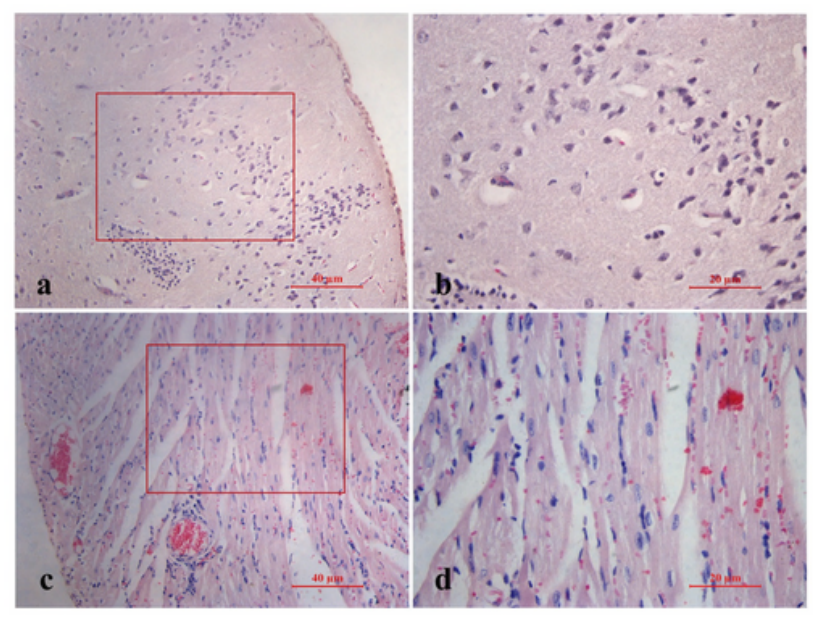

C

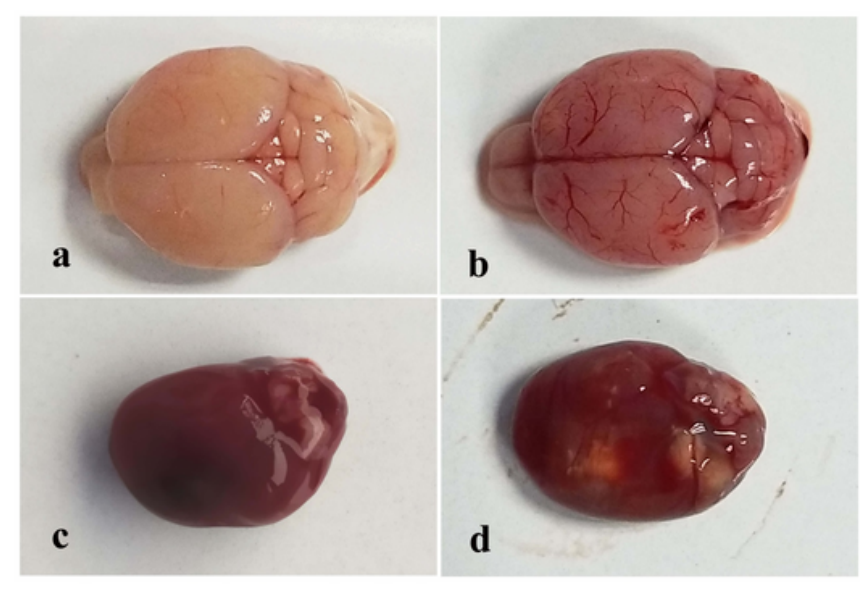

B

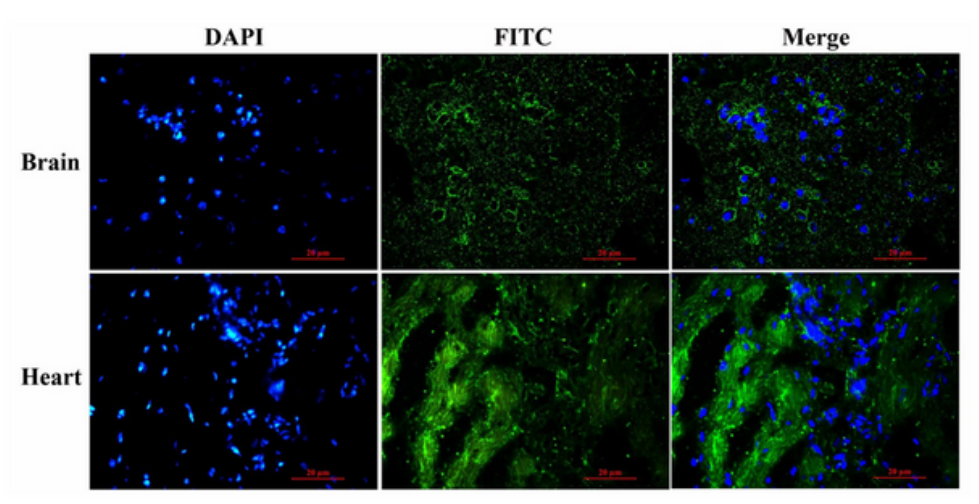

D

\section{Figure 3}

Characteristics of HLJ strain virus in vivo (A) Observation of clinical symptoms in mice. (a) negative control mice; (b) HLJ strain EMCV-infected mice. (B) Pathological lesions caused by HLJ strain in brain and heart organs of mice. (a) The brain of mice in the control group; (b) The brain of mice in the infected group; (c) The heart of mice in the in the control group; (d) The heart of mice in the infected group. (C) Histopathological changes of brain tissue (a and b) and myocardial tissue (c and d) of HLJ strain infected mice. (a, hematoxylin-eosin staining, HE. 20x magnification; b, HE. 40x magnification), (c, HE. 20x magnification; d, HE. 40x magnification). (D) The distribution of EMCV in the brain and heart of infected mice was detected by IFA. Green fluorescence is virus particles positive and blue is nuclear staining. Scale bar represents $20 \mu \mathrm{m}$. 


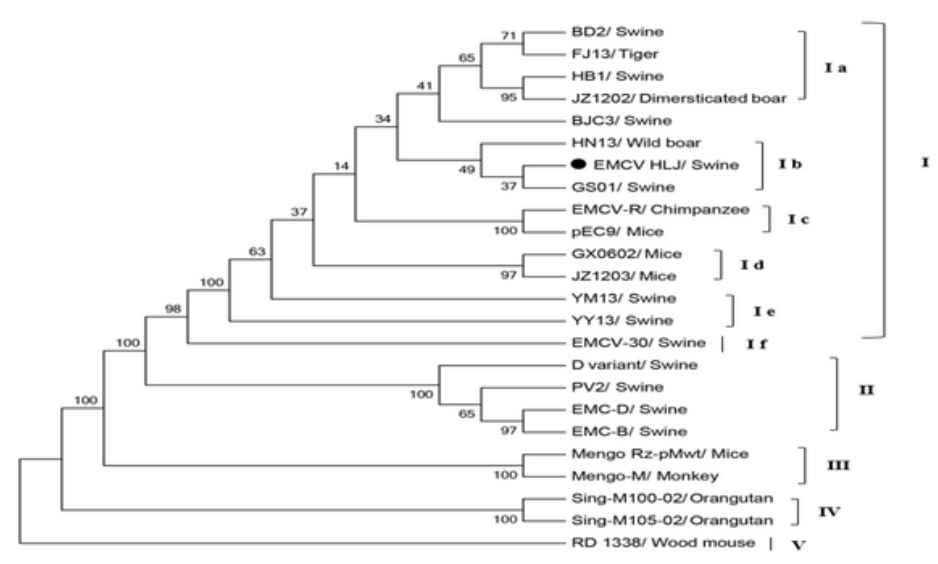

A

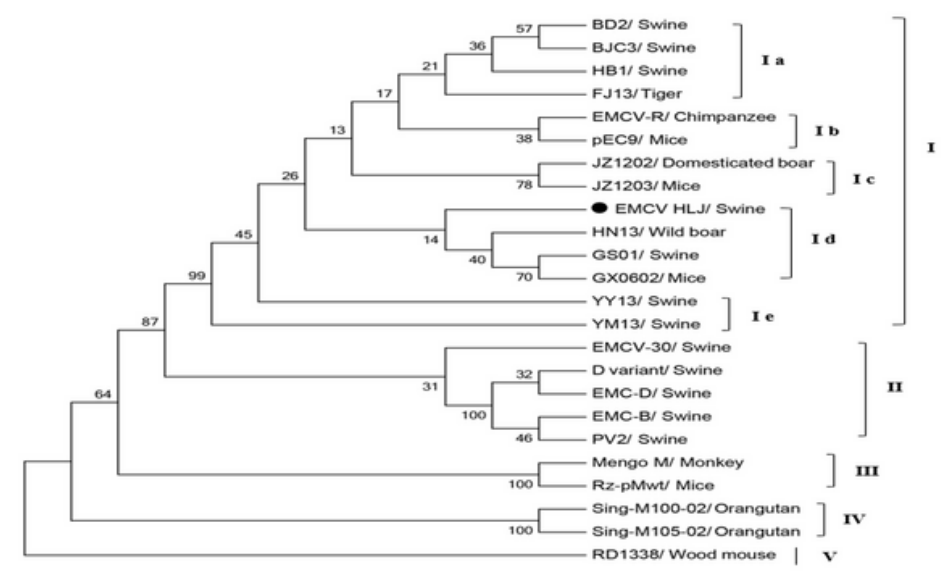

B

Figure 4

Phylogenetic relationship between HLJ strain and other EMCV strains Phylogenetic analysis of EMCV isolates based on the whole ORFs (A) and VP1 genes (B). The phylogenetic trees were constructed using neighbor-joining method by MEGA5 software. The isolate identified in this study is indicated with solid dots. Bootstrap values obtained from 1,000 replicates are shown at the major nodes.

\section{Supplementary Files}

This is a list of supplementary files associated with this preprint. Click to download.

- Additionalfile1.docx

- Additionalfile2.docx 